\title{
The Possibility and the Allowable Limit of Formation of Air Bubbles in the Sea
}

\author{
by \\ Y. Miyake \\ Meteorological Research Institute \\ (Received January 13, 1951)
}

\begin{abstract}
The formula expressing the saturation amount of the dissolved air in sea water was obtained. The result of calculation is given in Table 1. Since bubble formation in the sea depends on the pressure in situ, new concepts, the saturation amount in situ and the saturation percentage in situ were introduced. The possible causes of bubble formation were discussed and then graphical methods to compute the depth and the quantity of air to be evolved were obtained.
\end{abstract}

The problem of the formation of air bubbles in sea water seems to have become noteworthy in relation to the propagation of the sound since it was found experimentally that air bubbles exercise great influence upon the diminution of the supersonic waves in sea water. The author intends to report here briefly the result of study concerning the possibility and the allowable limit of formation of air bubbles in sea water.

\section{Dišsolved air in sea water}

Needless to say, the chief dissolved gases in sea water are nitrogen, oxygen and carbon dioxide. As to the nitrogen, the studies(1) up to the present show that it is in the state of almost nearly saturation at the normal pressure independent of the depth. Usually, the gas which is measured as simply nitrogen really contains rare gases such as argon. According to Fox the solubility of nitrogen in sea water of different temperature and chlorinity may be expressed as follows : (2)

$$
\begin{aligned}
V_{N} & =18.639-0.4304 t+0.00745 t^{2}-0.0000549 t^{3} \\
& -C l\left(0.2172-0.00718 t+0.0000952 t^{2}\right)
\end{aligned}
$$

Regarding the oxygen, sea water near the surface is usually saturated with it, but the rate of saturation decreases with the depth. In the layer containing many diatoms the super-saturation of oxygen often occurs, sometimes exceeding even $150 \%$. The solubility of oxygen in sea water is also given by Fox as follows. ${ }^{(3)}$

$$
\begin{aligned}
V_{0} & =10.291-0.2809 t+0.006009 t^{2}-0.0000632 t^{3} \\
& -C l\left(0.1161-1.003922 t+0.0000631 t^{2}\right)
\end{aligned}
$$

The problem of dissolution of carbon disoxide in sea water is rather complicated. 


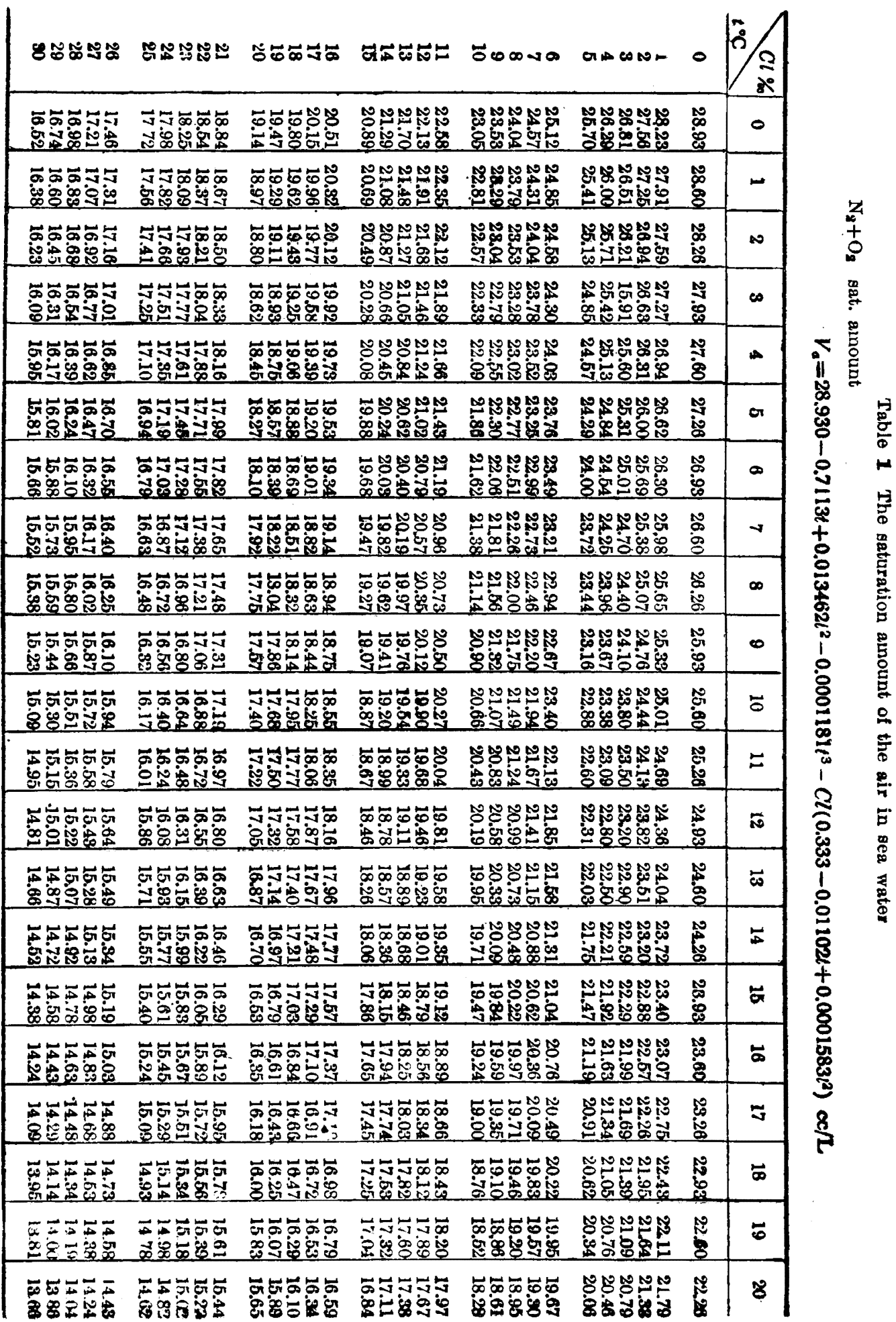


Since sea water contains much carbonate and bicarbonate and between those ions and dissolved free carbon dioxide there is an equilibrium. But, the partial pressure of free carbon dioxide in sea water is smaller than that in the air, that is only $0.15 \mathrm{~mm} \mathrm{Hg}$ by pressure. (4) Therefore, in discussing the dissolved air in sea water carbon dioxide may be negligible and it will be sufficient to take only nitrogen and oxygen into consideration.

In considering air bubbles in sea water, it is necessary to calculate the sum of the amount of nitrogen and oxygen. We can deduce the equation (3) of the solubility of air by combining above two equations. In Table 1 , results of calculation with the equation are given.

$$
\begin{aligned}
V_{a}= & 28.930-0.7113 t+0.013462 t^{2}-0.0001181 t^{3}-c l(0.333-0.01102 t \\
& \left.+0.0001583 t^{2}\right)
\end{aligned}
$$

\section{The rate of saturation of dissolved air in the sea}

The term, saturation percentage of gases used in the oceanography means the percent ratio of the quantity of the air actually dissolved in sea water to the saturation value at the same temperature and chlorinity, these values being both reduced to the normal state $\left(0^{\circ} \mathrm{C}, 1 \mathrm{~atm}\right.$. press. $)$.

In the sea, the hydrostatic pressure $p$ increases linearly with the depth, the change of which is very great as given in the next equation.

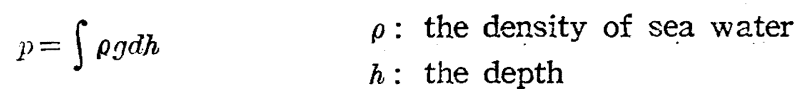

In other words, when the saturation percentage is $100 \%$ under $1 \mathrm{~atm}$. press., it becomes only $50 \%$ at the depth of $10 \mathrm{~m}$ since the pressure is about $2 \mathrm{~atm}$. press. at this depth. Therefore, in considering the formation of air bubbles, it is not sufficient to measure only the saturation percentage under $1 \mathrm{~atm}$.

Here, the author intends to propose the introduction of the following terms into oceanography, i. e., the saturation persentage in situ and saturation amount in situ. The saturation amount in situ is the saturation amount at a certain depth corresponding to the pressure (the sum of the hydrostatic pressure and atmospheric pressure), temperature and chlorinity in situ.

In distinction from terms, the saturation amount and the saturation percentage in the normal state should be called the normal saturation amount or percentage. Thus, in the range in which Henry's law holds,

Sat. Amount in situ=Press. in situ $\times$ Normal Sat. Amount

and the saturation percentage in situ is,

Sat. $\%$ in silu $=$ (Diss. Gas Amount / Sat. Amount in situ) $\times 100 \%$.

For example, when the super-saturation of oxygen up to $142 \%$ is observed at the depth of $10 \mathrm{~m}$ where the water temperature is $4.3^{\circ} \mathrm{C}$ and the chlorinity, $17.40 \%$, we can obtain as the saturation amount $a$, in situ as follows :

$$
a=42.0 \mathrm{cc} \text {. }
$$

On the other hand, as the normal saturation amount of nitrogen is $13.6 \mathrm{cc}$, the air dissolved in water is $21.3 \mathrm{cc}$ in total. Thus, the saturation percentage in situ 
becomes $57.8 \%$. Therefore, though oxygen is considerably super-saturated, bubbles can not form in such water as long as it remains at the depth.

3. The possible causes of the formation of bubbles in the sea

(a) The elevation of temperature

The elevation of temperature brings the decrease of saturation amount of the air as follows :

$$
d V / d t=-0.7113+0.026924 t-0.0003543 t^{2}+C l(0.01102-0.000316 t) \cdots \cdots(4)
$$

The elevation of $1^{\circ} \mathrm{C}$ corresponds to the decrease of $0.22 \mathrm{cc}$ of the air per litre when the chlorinity is $20 \%$ and the temperature, $10^{\circ} \mathrm{C}$

(b) The increase of chlorinity

The saturation amount decreases with the increase of the chlorinity,

$$
d V / d C l=-0.333+0.01102 t-0.0001583 t^{2}
$$

As the right side of the above equation is independent of the chlorinity and depends only on the temperature, the decrease of $1 \%$ of the chlorinity brings about the decrease of $0.23 \mathrm{cc}$ of the air per litre when the water temperature is $10^{\circ} \mathrm{C}$.

(c) The mixing of different water masses

The possibility of bubble formation will be brought about when different water masses with different temperature and chlorinity mix together. For example, suppose that there are some river water at $13^{\circ} \mathrm{C}$ and the sea water at $17.5^{\circ} \mathrm{C}$ with the chlorinity $19 \%$ and they are both saturated with air. When they mix together, excessive air will be formed, its volume varying with the mixing ratio, as is shown in the next table.

Table 2

\begin{tabular}{l|ccccccccc}
\hline River water \% & 90 & 80 & 70 & 60 & 50 & 40 & 30 & 20 & 10 \\
\hline Sea water \% & 10 & 20 & 30 & 40 & 50 & 60 & 70 & 80 & 90 \\
\hline $\begin{array}{l}\text { Excess arnount of } \\
\text { the air. } \Delta a \mathrm{cc} / L\end{array}$ & 0.08 & 0.11 & 0.16 & 0.16 & 0.19 & 0.16 & 0.16 & 0.11 & 0.08 \\
\hline
\end{tabular}

\section{(d) Miscellaneous}

As causes of forming bubbles in sea water, we may mention, among others, the upwelling current, the biological action, the putrefaction of the bottom deposit, the volcanic action under water etc. However, these causes are rather unusual and so do not deserve special mention.

\section{A graphical method to compute the quantity of air bubbles and the depth of their generation}

As mentioned above, it is not the normal saturation percentage but the saturation percentage in situ which determines the formation of bubbles in the sea. The possibility arises at the moment when the dissolved amount of the air exceeds the saturation amount in situ.

In Fig. 1 the straight line $A$ gives the normal saturation amount at $t_{1}^{\circ} \mathrm{C}$ and by the straight line $\mathrm{B}$ the saturation percentage in situ at the same temperature is 
1951 The Possibility and the Allowable Limit of Formation of Air Bubbles in the Sea

$$
C L=\text { const. }
$$

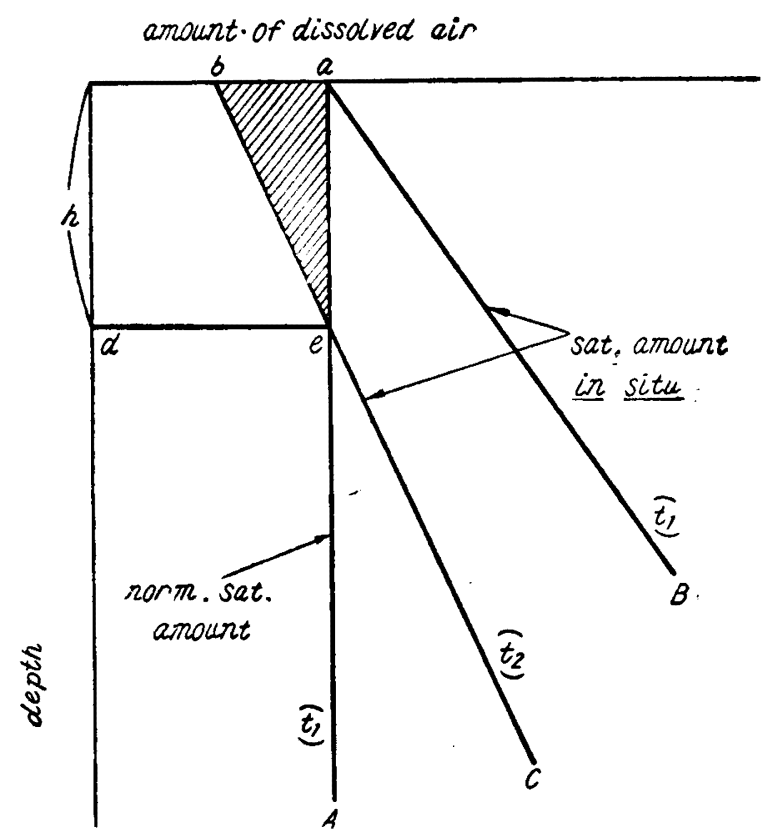

Fig. 1 A graph to obtain the anout of the excess air caused by the change of temperature

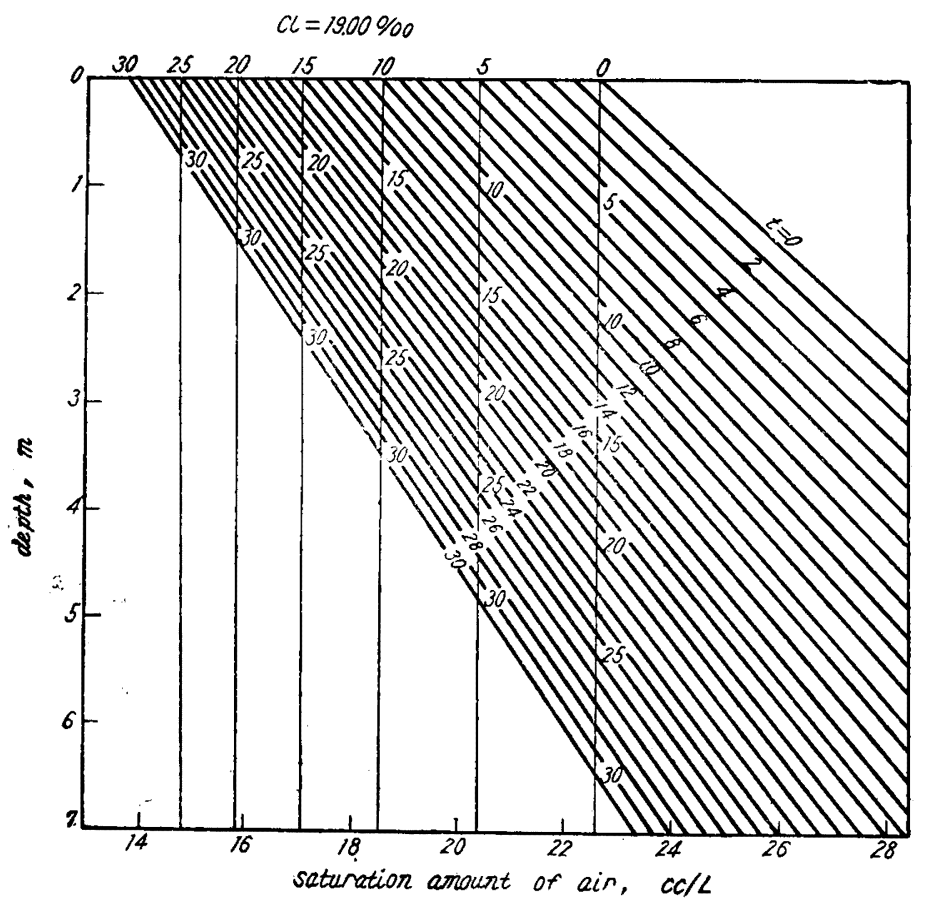

Fig. 2 A graph to obtain the amount of the excess air cansed by the change of temperature 


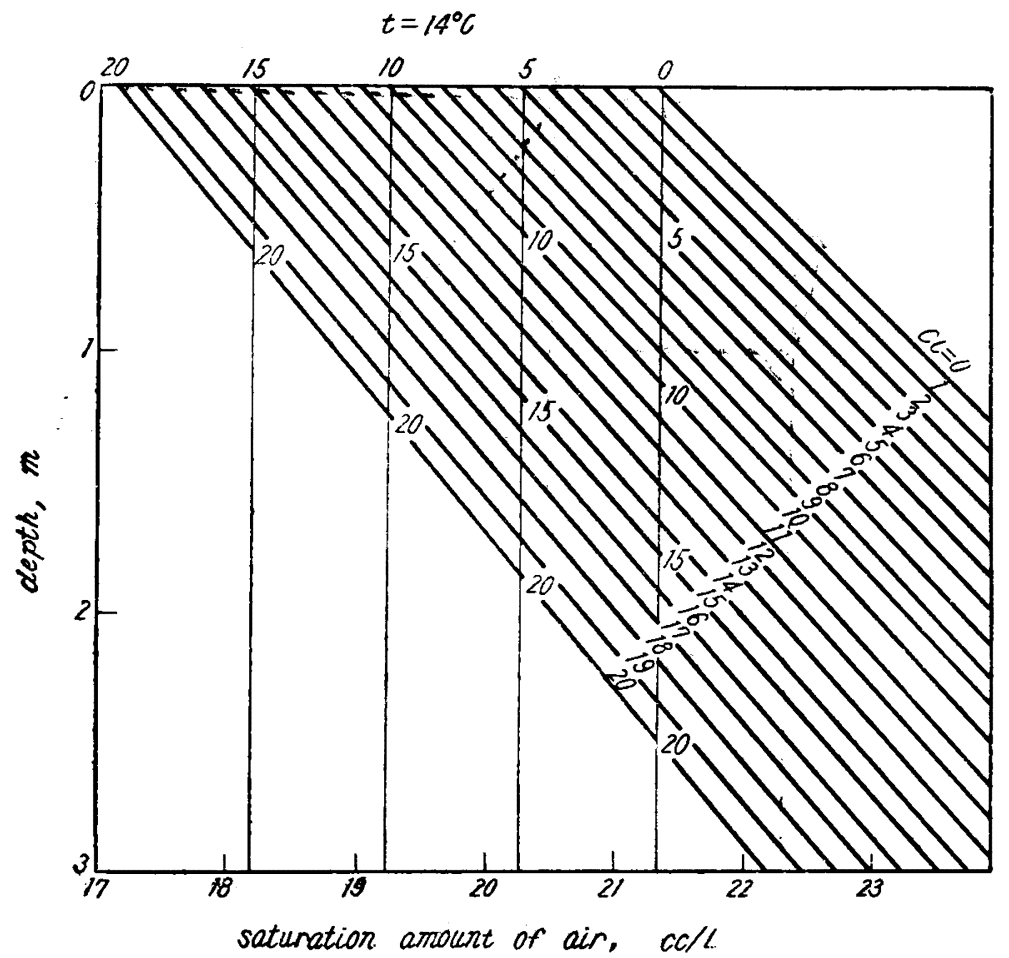

Fig. 3 A graph to obtain the amount of the excess air caused by the increase of chlorinity

given. Suppose that the water is homogeneous and saturated with air until a certain depth. When the temperature rises from $t_{1}$ to $t_{2}$ keeping the chlorinity constant, the saturation amount at $t_{2}$ becomes as shown by the straight line $\mathrm{C}$. Therefore, the air per unit volume of water is given by the triangle, and $\triangle a b c$ and the point $c$ shows the lowest limit of bubble formation. When the depth is measured in meter and the dissolved amount of air is given in $c c / L$, the surface of the triangle $\triangle a b c$ gives the amount of the air to be evolved from the unit water surface $\left(1 \mathrm{~m}^{2}\right)$ to the atmosphere.

In this wy, we can easily compute the amount of evolving air and the lower limit of bubble formation caused by the change of temperature of water with different chlorinities. For example, the amount of evolving air and the lower limit of evolution can be obtained by Fig. 2 when the chlorinity is $19 \%$.

In the same way, the amount of excess air and the lower limit of bubble formation caused by the change in chlorinity is given in Fig. 3, where the water temperature is $14^{\circ} \mathrm{C}$.

For instance, when the water temperature is raised from $10^{\circ} \mathrm{C}$ to $20^{\circ} \mathrm{C}$, we can estimate by Fig. 2 that the volume of evolving air is $2.2 \mathrm{~L} / \mathrm{m}^{2}$ and the lower limit is $1.7 \mathrm{~m}$ from the surface. When chlorinity changes from $15 \%$ os to $20 \%$, the evolving air is $0.3 \mathrm{~L} / \mathrm{m}^{2}$ and the lower limit is $0.6 \mathrm{~m}$. (Fig. 3 ) 


\section{References}

1) E. H. Randall, T. G. Thompson: J. Marine Research, 4 (1941), 11.

N. W. Rakestraw, V. M. Emmel: J. Marine Research, 1 (1938) 207.

z) D. F. Sinith: Int. Crit. Tables, 3 (1928), 271.

3) N. E. Dorsey: Properties of Ordinary Water Substance. p. 548 (1940).

4) H W. Harvey: Biological Chemistry \& Physics of Sea Water. p.64 (1928). 